\title{
Quantification of the Effects of Alternating and Simultaneous Red and Blue Irradia- tions on Plant Morphology and Shoot Fresh Weight in Leaf Lettuce 'Greenwave'
}

\author{
Kaito MASUdA, Hiroshi NAKASHIMA, Juro MiYASAKA and Katsuaki OHDOI \\ Graduate School of Agriculture, Kyoto University, Kyoto 606-8502, Japan
}

(Received October 21, 2020; Accepted April 9, 2021)

\begin{abstract}
A mechanism of increasing the shoot fresh weight (SFW) of leaf lettuce under alternating red (R) and blue (B) irradiation by light-emitting diodes (LEDs) was investigated based on plant morphogenesis. Seedlings of leaf lettuce (Lactuca sativa L. var. crispa 'Greenwave') were cultivated under seven alternating irradiations, i.e., R24B0, R20B4, R16B8, R12B12, R8B16, R4B20 and R0B24, in which RxBy implies $x$ and $y$ hours of irradiation for red and blue LEDs, respectively. The results of these treatments were compared to those of two simultaneous irradiations: one containing no dark periods and the other containing a 12-hour period, i.e., sR24B24 at a photosynthetic photon flux density (PPFD) of $100 \mu \mathrm{mol} \mathrm{m}$ $\mathrm{s}^{-1}$, and $\mathrm{sR} 12 \mathrm{~B} 12$ at a PPFD of $200 \mu \mathrm{mol} \mathrm{m} \mathrm{m}^{-1}$. Multiple regression analysis was conducted to investigate the causal relationship between the plant morphological characteristics (PMs) and SFW. The increase in the number of leaves with the red-light period in alternating irradiation treatments increased the total leaf area and consequently the SFW. On the other hand, the difference between PMs in alternating and simultaneous irradiations depended on the individual leaf area (ILA), where ILA under alternating irradiation treatments was significantly larger compared to that under simultaneous irradiation treatments.
\end{abstract}

Keywords : light-emitting diode, light quality, multiple regression analysis, photomorphogenesis, plant factory

\section{INTRODUCTION}

In the closed-type plant factories, artificial light sources, such as fluorescent lamps and light-emitting diodes (LEDs), are widely used as alternatives to sunlight. They, along with setting optimum environmental conditions (light, temperature, humidity, $\mathrm{CO}_{2}$, concentration of nutrient solution, and so on), can improve the productivity per unit area, and consequently increase the profit from small cultivation areas (Goto, 2012). However, only a few enterprises make a profit, due to the high initial cost for construction of closed-type plant factory units and the running costs of electric power such as lighting and air conditioning (Benke and Tomkins, 2017; Kozai, 2013).

To reduce the running cost, LEDs are used as artificial light sources for plant growth, because of their lower power consumption and longer life span compared to fluorescent lamps. The morphogenesis of plants depends on the light spectra, and the illumination of LEDs is composed of a narrow range of wavelengths on the electromagnetic spectrum. Chlorophylls in plants mainly absorb red and blue lights and perform photosynthesis (Mohr and Schopfer, 1998); thus, several previous studies investigated the ability to increase yields by enhancing the efficiency of using these two colors. Shimokawa et al. (2014, 2020) investigated the growth of three cultivars of leaf lettuce, i.e., Summer Surge, Black Rose, Green Span (Lactuca sativa L. var. crispa) using Shigyo's method, which involves alternating irradiation with red (LED; $660 \mathrm{~nm}$, $100 \mu \mathrm{mol} \mathrm{m} \mathrm{s}^{-1}$ ) and blue (LED; $450 \mathrm{~nm}, 60 \mu \mathrm{mol} \mathrm{m}{ }^{-2}$ $\mathrm{s}^{-1}$ ) lights. They found that this method enhanced the growth of two cultivars, i.e., Summer Surge and Black Rose, by increasing SFW compared to those under fluorescent light or simultaneous irradiation with red and blue lights. Using romaine lettuce (Lactuca sativa L. cv. Cos Lettuce), Jishi et al. (2016) examined the irradiation patterns of various combinations of red (LED, $90 \mu \mathrm{mol} \mathrm{m}{ }^{-2}$

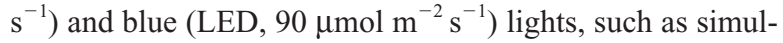
taneous red-blue irradiation as well as irradiation with shifted red-light period, based on the study of Hanyu and Shoji (2002), in which they found that using blue light irradiation just before entering the light period promoted the growth of spinach. When a photoperiod was set using a cycle of blue monochromatic light; red monochromatic light; and dark period, the total leaf area and SFW were maximized. Kuno et al. (2017) investigated the cultivation of leaf lettuce (Lactuca sativa L. var. crispa 'Greenwave') under simultaneous irradiation, alternating irradiation and shifted irradiation of red (LED, $120 \mu \mathrm{mol} \mathrm{m}^{-2} \mathrm{~s}^{-1}$ ) or blue (LED, $120 \mu \mathrm{mol} \mathrm{m}{ }^{-2} \mathrm{~s}^{-1}$ ) light periods. The SFW obtained using alternating irradiation was significantly larger compared to that obtained using simultaneous irradiation. The SFW obtained using red monochromatic light was also large. Takasu et al. (2019) examined the optimum conditions for using alternating irradiations (ALTs) to cultivate Lactuca sativa L. var. crispa 'Greenwave' under nine different ratios of red light (LED, $100 \mu \mathrm{mol} \mathrm{m}^{-2} \mathrm{~s}^{-1}$ ) and blue

Corresponding author: Kaito Masuda,

e-mail : masuda.kaito.27m@st.kyoto-u.ac.jp 
light (LED, $100 \mu \mathrm{mol} \mathrm{m} \mathrm{m}^{-2} \mathrm{~s}^{-1}$ ) irradiation periods. The maximum values of total fresh weight, SFW and shoot dry weight (SDW) were obtained at a 21:3 irradiation time ratio of red to blue lights, and no significant difference could be observed between the irradiation patterns near the irradiation period ratio of $21: 3$. In the study, only six experimental treatments could be cultivated at the same time because of the limitation of experimental equipment. Therefore, it is necessary to carry out cultivation and verification in the same experiment, because the comparison in the aforementioned study was carried out between a few experiments conducted under slightly different conditions. In addition, the relation between SFW and PA/LA, which is a ratio of the projected leaf area (PA) to the total leaf area (LA) and indicates leaf angle and overlapping, was investigated to clarify the mechanism of growth promotion by ALTs.

The plant morphological mechanism for growth promotion of leafy vegetables, especially leaf lettuce, by ALTs compared with simultaneous red and blue irradiations (SIMs) is still not fully understood (Jishi et al., 2016; Kuno et al., 2017; Ohtake et al., 2018; Shimokawa et al., 2014, 2020; Takasu et al., 2019). Therefore, in this study, the main plant morphological factors of growth promotion by ALTs as well as the optimum ratio of alternating red and blue irradiation were examined. This was conducted by quantifying the plant morphological characteristics (PMs) and investigating the cause of the large difference in their SFW between using ALTs and SIMs. Furthermore, the irradiation conditions under which SFW increased were investigated with change in the ratio of the irradiation time of red and blue lights in alternating irradiations using multiple regression analysis in order to clarify the effect of the PMs on the SFW. The study investigated the mechanism through which irradiation conditions affect morphology and weight at harvest, and a no time-series growth analysis was conducted because of the limitation on the data scale. This study will contribute to reduce the cultivation period and the running cost in the plant factory.

\section{MATERIALS AND METHODS}

\section{Plant materials and conditions}

Experiments were conducted in an environmental controlled room $(2 \mathrm{~m}$ width $\times 5 \mathrm{~m}$ depth $\times 2.5 \mathrm{~m}$ height, TAF24KS, ESPEC MIC Co.). The environmental conditions in each growth stage are shown in Table 1. Seeds of leaf lettuce (Lactuca sativa L. var. crispa 'Greenwave', ALE539; TAKII \& Co., Ltd., Kyoto, Japan, 300 seeds) were seeded on urethane sponges soaked in a nutrient solution in a plastic tray $(150 \mathrm{~mm}$ width $\times 250 \mathrm{~mm}$ depth $\times 50 \mathrm{~mm}$ height $)$ and subjected to a dark treatment for 1 day followed by a germination treatment for 7 days. Then, 150 seedlings were transplanted to the nursing panel ( 90 holes, 600 $\mathrm{mm} \times 600 \mathrm{~mm}$ ) where the deep flow technique (DFT) was applied, and a nursery treatment was carried out for 7 days. The photosynthetic photon flux density (PPFD) of the light environment during the germination and nursery treatments was set to $100 \pm 10 \mu \mathrm{mol} \mathrm{m} \mathrm{m}^{-2} \mathrm{~s}^{-1}$ with a light period/dark period of 16 hours/ 8 hours that was obtained using three white LED bars (EM1134660 fluorescent LED for plant growth, ESPEC MIC Co., Aichi, Japan). After the nursery treatment, a total of 90 seedlings were placed in 9 sections (10 seedlings/section) to undergo an experimental treatment applied the DFT and grown for 14 days under each experimental condition. The cultivation panel had 30 holes, its size was $670 \mathrm{~mm} \times 1,300 \mathrm{~mm}$, and the distance between plants was $220 \mathrm{~mm}$ (Fig. 1a). The details of the LED bar placement and the maximum distance between the light source and the plant are depicted in Fig. 1a and $b$. The temperature was set to $21.5 \pm 1.0^{\circ} \mathrm{C}$ and the humidity was set to $85 \pm 5 \%$ during all treatments. Nutrient water was used for germination, nursing, and cultivation (OAT house; A prescription or SA prescription used, OAT Agrio, Tokyo, Japan). The $\mathrm{pH}$ and electrical conductivity (EC) were maintained at $6.5 \pm 0.5$ and $1.5 \pm 0.1 \mathrm{dS} \mathrm{m}^{-1}$ in the germination treatment, and $6.3 \pm 0.5$ and $1.5 \pm 0.1 \mathrm{dS} \mathrm{m}^{-1}$ in the nursery treatment. In the experimental treatment, the $\mathrm{pH}$ and EC were maintained at $6.7 \pm 0.5$ and $2.0 \pm 0.1 \mathrm{dS}$ $\mathrm{m}^{-1}$, respectively.

Table 1 Environmental conditions in each growth stage.

\begin{tabular}{|c|c|c|c|c|}
\hline Growth stage & Sowing & Germination & Nursing & Cultivation \\
\hline Date (d) & $0-1$ & $1-8$ & $8-15$ & $15-29$ \\
\hline Hydroponic system & Passive $^{z}$ & Passive & DFT & DFT \\
\hline Light sources (LED) & Nothing & White & White & Red and Blue \\
\hline PPFD $\left(\mu \mathrm{mol} \mathrm{m}{ }^{-2} \mathrm{~s}^{-1}\right)$ & 0 & $100 \pm 10$ & $100 \pm 10$ & $100 \pm 5$ \\
\hline $\begin{array}{c}\text { Photoperiod (h) } \\
\text { Light/Dark }\end{array}$ & $0 / 24$ & $16 / 8$ & $16 / 8$ & Seeing Fig. 2 \\
\hline $\mathrm{pH}$ & $6.5 \pm 0.5$ & $6.5 \pm 0.5$ & $6.3 \pm 0.5$ & $6.7 \pm 0.5$ \\
\hline $\mathrm{EC}\left(\mathrm{dS} \mathrm{m}{ }^{-1}\right)$ & $1.5 \pm 0.1$ & $1.5 \pm 0.1$ & $1.5 \pm 0.1$ & $2.0 \pm 0.1$ \\
\hline Air temperature $\left({ }^{\circ} \mathrm{C}\right)$ & & $21.5 \pm 1.0$ & & \\
\hline Humidity (\%) & & $85 \pm 5$ & & \\
\hline $\begin{array}{l}\mathrm{CO}_{2} \text { concentration } \\
\left.(\mu \mathrm{mol} \mathrm{mol})^{-1}\right)\end{array}$ & & Not controlled & & \\
\hline
\end{tabular}

${ }^{\mathrm{z}}$ Passive: There was no flow in water. 


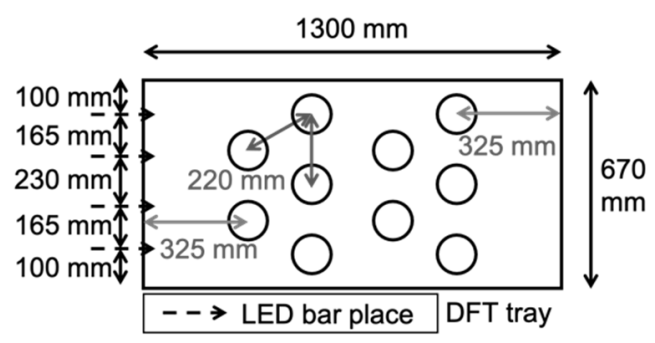

(a) Planting density and LED bar placement

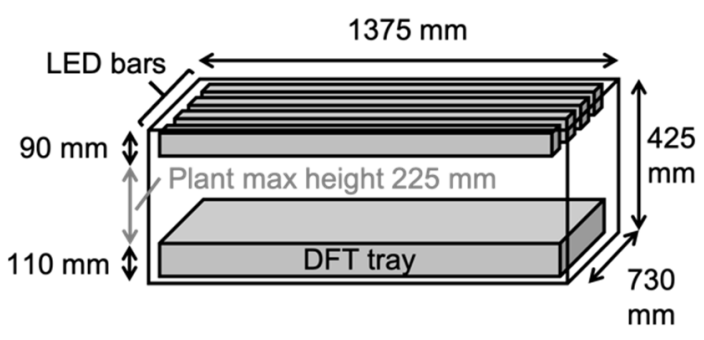

(b) Size of cultivation equipment

Fig. 1 Cultivation equipment in the experimental treatment at each section.

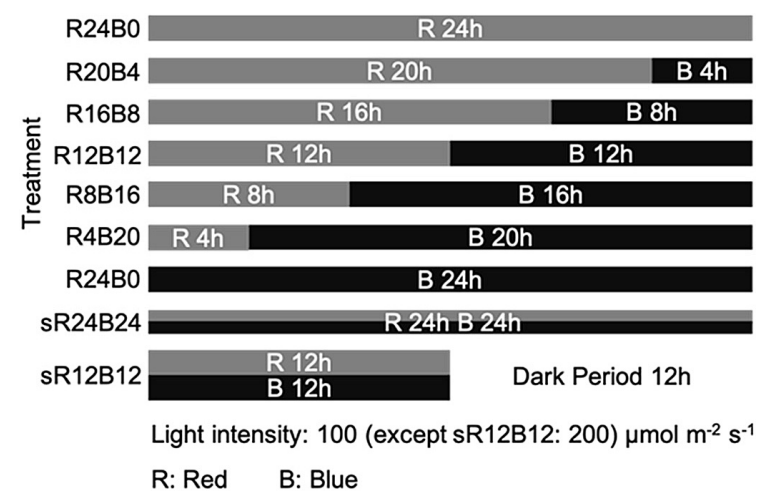

Fig. 2 The irradiation patterns in the experiment.

\section{Light treatments}

Four red (660 nm) and blue (450 nm) LED bars (LED bar units for plant growth, Ushio Lighting Co., Ltd.) were used in each section in all experimental treatments. Figure 2 shows the irradiation patterns in each experimental treatment. The alternating irradiation cycle was labelled as $\mathrm{R} x \mathrm{~B} y$, where $x$ and $y$ are the irradiation periods of red and blue lights in hours, respectively. Therefore, seven alternating irradiation groups were set as in the figure, i.e., R24B0, R20B4, R16B8, R12B12, R8B16, R4B20 and R0B24 with a consistent PPFD of $100 \pm 5 \mu \mathrm{mol} \mathrm{m} \mathrm{m}^{-2} \mathrm{~s}^{-1}$. Moreover, two groups of the simultaneous irradiation were set: the first group of no dark periods (sR24B24; each red and blue light PPFD of $50 \pm 2.5 \mu \mathrm{mol} \mathrm{m} \mathrm{m}^{-2} \mathrm{~s}^{-1}$ ), and the other with a dark period of 12 hours (sR12B12; each red and blue light PPFD of $\left.100 \pm 5 \mu \mathrm{mol} \mathrm{m} \mathrm{m}^{-2} \mathrm{~s}^{-1}\right)$. The reason for setting sR12B12 is that leaf lettuce is a plant that inherently requires a dark period, and we used it as a control for experiments with continuous light other than sR12B12. The same daily light integral was used in all experimental treatments. There was no light leakage or contamination in any of the experimental conditions because each section was covered with light-reflecting and shielding sheets.

\section{Measurements}

Total fresh weight inclusive of a sponge for seeding, SFW and SDW (drying at $103^{\circ} \mathrm{C}$ for 24 hours) were measured as indicators of plant growth. Total leaf area (TLA), number of leaves (NL), leaf length and stem length were measured as PMs by taking photos and using an opensource ImageJ software (ImageJ, 2018). The example of leaves and stem are shown in Fig. 3. These measurements were performed on $3-\mathrm{cm}$ or larger leaves. Three ratios were used as indicators: the shoot dry matter ratio (\%), which is the ratio of SDW to SFW; the individual leaf area (ILA), which is the ratio of TLA to NL; and specific leaf area (SLA), which is the ratio of TLA to SDW. Using the total leaf volume (TLV), leaf thickness (LT), and leaf density (LD), TLA and SDW can be expressed as Eqs. 1 and 2, respectively. From Eqs. 1 and 2, SLA is an indicator of LT or LD (Eq. 3). The ILA and SLA were treated as PMs.

$$
\begin{aligned}
T L A & =\frac{T L V}{L T} \\
S D W & =T L V \times L D \\
S L A & =(L T \times L D)^{-1}
\end{aligned}
$$

\section{Statistical analysis}

The mean \pm standard deviation (SD) of 10 seedlings was calculated for all measurements except the leaf length in each section, and Tukey's multiple comparisons were conducted at a significance level of 5\%. The leaf length was analyzed by 1 -way ANOVA at a significance level of $5 \%$ within each section, and after confirming that there was no variation among the sections, Tukey's multiple comparisons were conducted at a significance level of $5 \%$.

Multiple regression analysis

We investigated the causal relationship between PMs and SFW. PMs are affected by the distribution of photosynthetic products, and this distribution is controlled by photoreceptors, i.e., LED irradiation patterns. By clarifying this causal relationship, we can determine how the irradiation method affects plant morphology and which factors of plant morphology have a strong effect on SFW. A linear multiple regression analysis (Eq. 4) was performed using the following five variables as the explanatory variables $x_{i}$ $(i \in \mathbb{N}, 1 \leq i \leq n=5)$ : TLA, NL, ILA, SLA, and stem length, which are the PMs. Plant canopy and PA were not included as explanatory variables because they are formed by the combination of the aforementioned PMs, and multicollinearity can be excluded by eliminating intermediate variables in the causal flow in advance. The objective variable $y$ was SFW, which is the indicator for plant growth. 


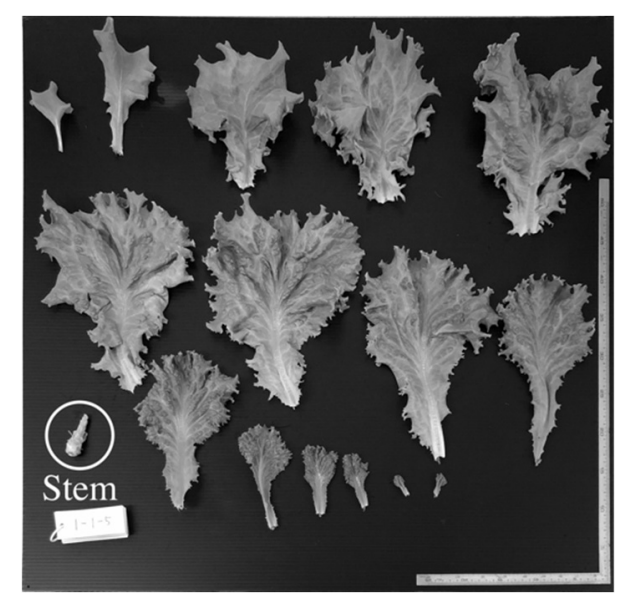

(a) $\mathrm{R} 24 \mathrm{~B} 0$

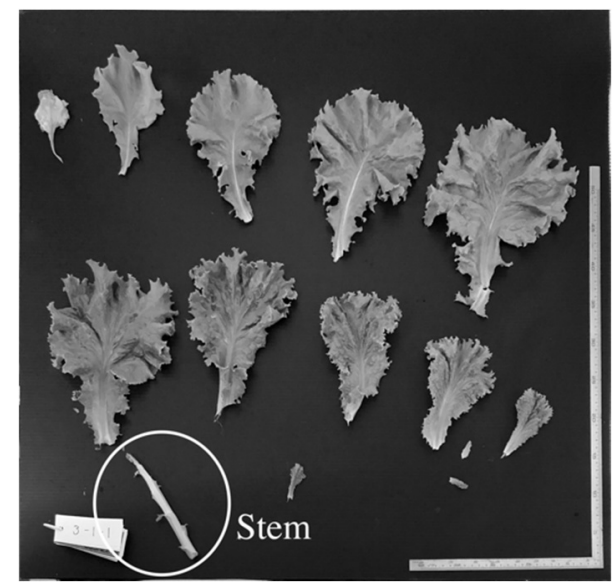

(c) R0B24

Fig. 3 The examples of leaves and stem.

$$
y=\sum_{i=1}^{n}\left(a_{i} x_{i}\right)+b
$$

The effect of PMs on the SFW was evaluated by comparing the magnitude of the absolute values of the standardized partial regression coefficients, i.e., $\left|a_{1}\right|, \cdots,\left|a_{n}\right|$ given by Eq. 4. The significance of the standardized partial regression coefficients was observed by $t$-test. The applicability of the multiple regression equation was evaluated using the adjusted multiple coefficient of determination $R^{2}$.

\section{Multicollinearity}

To investigate the multicollinearity that can occur when there are many explanatory variables into account, multiple regression analysis was performed using one of the explanatory variables as the objective variable and the rest as the explanatory variables. A statistic variance inflation factor $(V I F)$ shown in Eq. 5 was derived using the adjusted $R^{2}$ calculated, and the variable selection was performed.

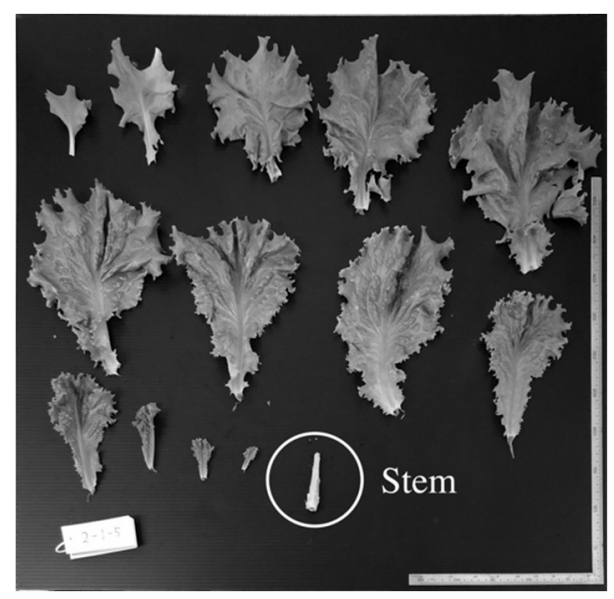

(b) R12B12

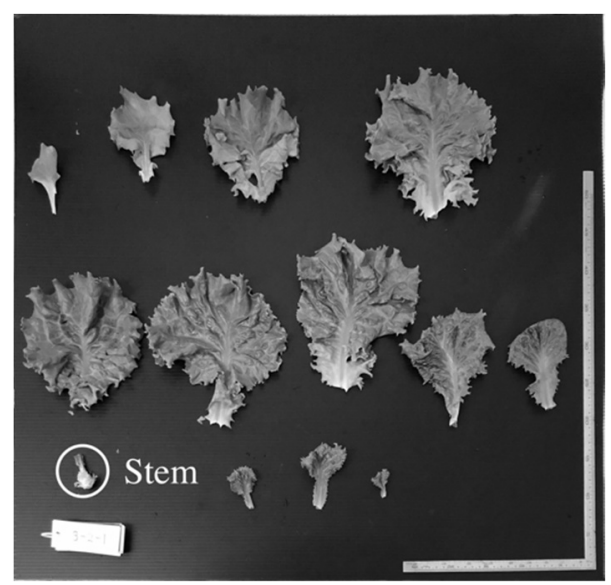

(d) sR24B24

$$
V I F=\frac{1}{1-R^{2}}
$$

The explanatory variable with the highest $V I F$ value was excluded at $V I F>10$. This operation was repeated until the multicollinearity was no longer recognized (Akinwande et al., 2015; Mansfield and Helms, 1982; Marquardt, 1970; O'Brien, 2007). In addition, the correlation coefficients of all combination between the objective variable and the explanatory variables were calculated to detect the suppressor variables in the explanatory variables, because VIF cannot detect them (Akinwande et al., 2015; O’Brien, 2007).

Model setting

In this study, two models were prepared for multiple regression analysis. The reason for setting up two models is discussed in the "Multicollinearity and multiple regression analysis" section based on the later RESULTS. One model (model 1) was based on the sole alternating red and blue irradiation treatments (70 plants in 7 sections), whereas the other model (model 2) was on all treatments 
MORPHOLOGY \& WEIGHT UNDER LEDs

Table 2 Effects of alternating red and blue irradiations on plant growth and plant morphological characteristics.

\begin{tabular}{|c|c|c|c|c|c|c|c|c|c|}
\hline Treatment & $\begin{array}{l}\text { Total fresh } \\
\text { weight }(\mathrm{g})\end{array}$ & $\begin{array}{r}\text { Shoot fresh } \\
\text { weight }(\mathrm{g})\end{array}$ & $\begin{array}{l}\text { Shoot dry } \\
\text { weight (g) }\end{array}$ & $\begin{array}{c}\text { Shoot dry } \\
\text { matter ratio } \\
(\%)\end{array}$ & $\begin{array}{l}\text { Total leaf } \\
\text { area }\left(\mathrm{cm}^{2}\right)\end{array}$ & $\begin{array}{c}\text { Number of } \\
\text { leaves } \\
\text { (/plant) }\end{array}$ & $\begin{array}{l}\text { Individual } \\
\text { leaf area } \\
\left(\mathrm{cm}^{2}\right)\end{array}$ & $\begin{array}{l}\text { Specific } \\
\text { leaf area } \\
\left(\mathrm{cm}^{2} / \mathrm{g}\right)\end{array}$ & $\begin{array}{l}\text { Stem } \\
\text { length } \\
(\mathrm{cm})\end{array}$ \\
\hline $\mathrm{R} 24 \mathrm{~B} 0$ & $112.11 \mathrm{a}$ & $97.74 \mathrm{a}$ & $4.07 \mathrm{a}$ & $4.16 \mathrm{~d}$ & $2,061.0 \mathrm{a}$ & $14.7 \mathrm{a}$ & $142.8 \mathrm{a}$ & $509.07 \mathrm{a}$ & $4.84 \mathrm{~d}$ \\
\hline R20B4 & $110.47 \mathrm{ab}$ & $94.02 \mathrm{a}$ & $4.05 \mathrm{a}$ & $4.31 \mathrm{~cd}$ & $1,869.6 \mathrm{ab}$ & $13.2 \mathrm{ab}$ & $141.7 \mathrm{a}$ & $464.51 \mathrm{ab}$ & $5.17 \mathrm{~d}$ \\
\hline R16B8 & $106.75 \mathrm{ab}$ & $89.82 \mathrm{ab}$ & $3.96 \mathrm{ab}$ & $4.41 \mathrm{~cd}$ & $1,719.8 \mathrm{bc}$ & $12.4 \mathrm{bcd}$ & $139.5 \mathrm{a}$ & $435.67 \mathrm{bcd}$ & $5.78 \mathrm{~cd}$ \\
\hline $\mathrm{R} 12 \mathrm{~B} 12$ & $101.13 \mathrm{abc}$ & $85.19 \mathrm{abc}$ & $3.87 \mathrm{ab}$ & $4.54 \mathrm{bcd}$ & $1,718.4 \mathrm{bc}$ & $12.4 \mathrm{bcd}$ & $138.8 \mathrm{a}$ & $444.99 \mathrm{bc}$ & $6.38 \mathrm{~cd}$ \\
\hline R8B16 & $94.73 \mathrm{bcd}$ & $78.64 \mathrm{bcd}$ & $3.90 \mathrm{ab}$ & $4.94 \mathrm{ab}$ & $1,609.5 \mathrm{bc}$ & $11.7 \mathrm{bcd}$ & $137.6 \mathrm{a}$ & $417.09 \mathrm{bcd}$ & $7.52 \mathrm{c}$ \\
\hline R4B20 & $90.45 \mathrm{~cd}$ & $74.93 \mathrm{~cd}$ & $3.60 \mathrm{ab}$ & $4.85 \mathrm{ab}$ & $1,499.1 \mathrm{~cd}$ & $11.4 \mathrm{~cd}$ & $132.3 \mathrm{a}$ & $420.10 \mathrm{bcd}$ & $9.86 \mathrm{~b}$ \\
\hline R0B24 & $81.52 \mathrm{~d}$ & $68.06 \mathrm{~d}$ & $3.33 \mathrm{~b}$ & $4.91 \mathrm{ab}$ & $1,314.9 \mathrm{~d}$ & $10.9 \mathrm{~cd}$ & $121.1 \mathrm{ab}$ & $396.14 \mathrm{~cd}$ & $12.25 \mathrm{a}$ \\
\hline sR24B24 & $83.95 \mathrm{~d}$ & $69.05 \mathrm{~d}$ & $3.27 \mathrm{~b}$ & $4.74 \mathrm{abc}$ & $1,267.4 \mathrm{~d}$ & $12.8 \mathrm{~b}$ & 99.6 bc & $387.47 \mathrm{~d}$ & $3.18 \mathrm{de}$ \\
\hline sR12B12 & $60.33 \mathrm{e}$ & $47.21 \mathrm{e}$ & $2.41 \mathrm{c}$ & $5.10 \mathrm{a}$ & $939.1 \mathrm{e}$ & $11.4 \mathrm{bcd}$ & $82.4 \mathrm{c}$ & $391.34 \mathrm{~cd}$ & $1.85 \mathrm{e}$ \\
\hline
\end{tabular}

Different letters indicate significant differences at Tukey's multiple comparisons $(P<0.05, n=10)$.

(90 plants in 9 sections; 70 plants in 7 sections of alternating irradiation treatments and 20 plants in 2 sections of simultaneous irradiation treatments).

\section{RESULTS}

Effects of alternating red and blue irradiations on the plant growth and morphological characteristics

Table 2 shows the results of plant growth and PMs. Under ALTs, the total fresh weight, SFW, SDW and TLA were larger at longer irradiation period of red light. No significant differences were found between R24B0, R20B4, $\mathrm{R} 16 \mathrm{~B} 8$, and R12B12 for the groups with the highest total fresh weight and SFW. There was no significant difference between the SDWs under ALTs except for R0B24. Groups grown under R24B0 and R20B4 conditions had the highest values of TLA, and no significant difference was found between them. Under SIMs, the SDW, total fresh weight, and SFW of sR24B24 were significantly larger compared to those of sR12B12. Moreover, the TLA grown under sR12B12 was minimized, and the TLA grown under sR12B12 was significantly smaller compared to that grown under sR24B24.

The maximum of shoot dry matter ratio under ALTs was R8B16. In all treatments, the shoot dry matter ratio was maximized under sR12B12. The NL increased as the irradiation time of red light increased under ALTs. On the other hand, the NL under sR24B24 of SIMs was significantly larger compared to those under R4B20 or R0B24. There was no significant difference for ILA grown under each ALTs and SIMs. At the same time, there was a significant difference between ILAs under ALTs and SIMs except for R0B24. Under ALT, SLA tended to increase as the duration of red-light exposure increased. The minimum SLA in both ALTs and SIMs was found under sR24B24. The stem length became increased with the irradiation time of the blue light under ALTs, and the leaf lettuce grown under R0B24 showed significantly longer stem length compared to those cultivated under other irradiation conditions. In addition, stem lengths under SIMs were significantly shorter compared to those under ALTs, which included the blue light.

\section{Leaf lengths}

Figure 4a shows the box plot of the leaf length at each plant in ALTs and SIMs. The result of the 1-way ANOVA in each section indicated that the null hypothesis was not rejected in all irradiation treatments. Figure $4 \mathrm{~b}$ shows the frequency line graph of the dataset into which all leaf lengths in each section were compiled. Depending on the peak values, there were three characteristic types: ALTs, sR24B24, and sR12B12. The peaks in ALTs were $25.5 \mathrm{~cm}$, $16.5 \mathrm{~cm}, 10.5 \mathrm{~cm}$, and $4.5 \mathrm{~cm}$, and therefore plants under ALTs show the similar growth in terms of the leaf length distribution. The peaks in sR24B24 were at 19.5 and 4.5 $\mathrm{cm}$, whereas in sR12B12, there was a peak at $16.5 \mathrm{~cm}$. Figure $4 \mathrm{c}$ shows the bar graph of means and SD calculated based on the medians of leaf length per seedling with reference to Fig. 4a. The lower limit of the leaf length was set at $3 \mathrm{~cm}$, but there was no limit to the upper case, so the larger the maximum leaf length per seedling, the smaller the mean leaf length per seedling. Median values, not mean values, were used for this reason. The results of Tukey's multiple comparison showed that there was no significant difference in each ALTs and SIMs. However, there was a significant difference between ALTs and SIMs.

Multicollinearity and multiple regression analysis

Statistic VIFs of TLA, NL and ILA in both models 1 and 2 were greater than 10 to confirm the multicollinearity (Table 3). Since the statistic VIFs of the TLA in both models was greater than 100, the calculation of the statistic VIFS of PMs except for the TLA was repeated, and the statistic VIFs for four explanatory variables was less than 10 . Thus, no multiple collinearity was observed.

From the results obtained thus far, two hypotheses were constructed. First, it was hypothesized that the NL of plants cultivated under ALTs increased with the irradiation time of red light, which led to the increase in the TLA and subsequently SFW (hypothesis 1). Second, it was also hypothesized that ALTs could enlarge the field of photosynthesis by increasing the ILA compared to SIMs, which resulted in an increase in the SFW (hypothesis 2). The consistency of the hypotheses 1 and 2 was confirmed by the multiple regression analysis in models 1 and 2, respectively. 


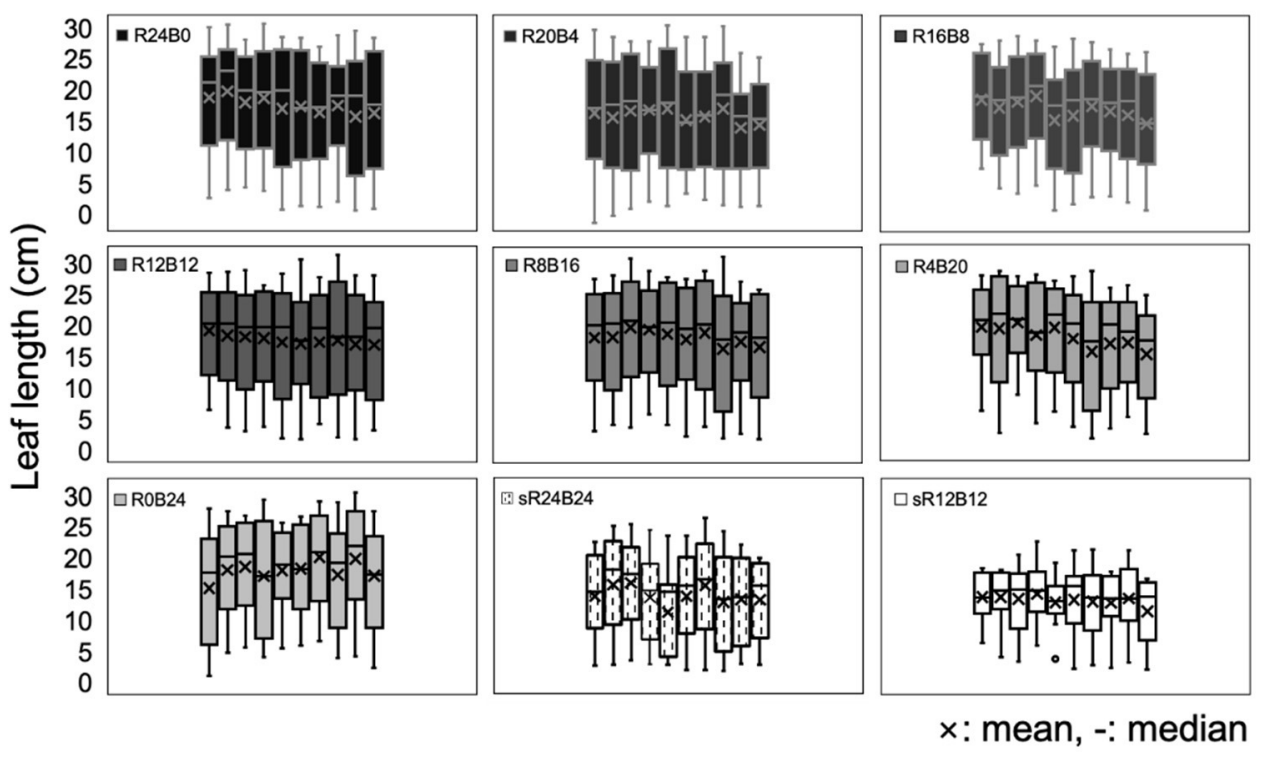

(a) Box plot of leaf length at each plant

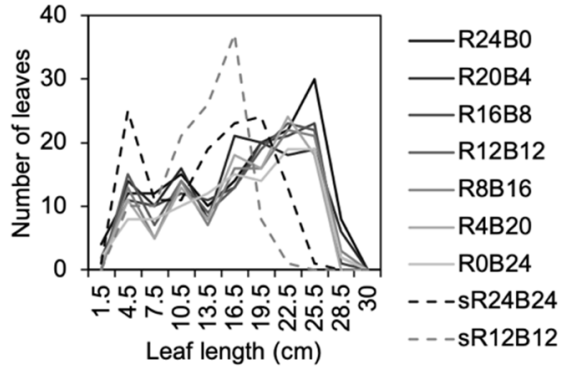

(b) Frequency line graph of leaf length

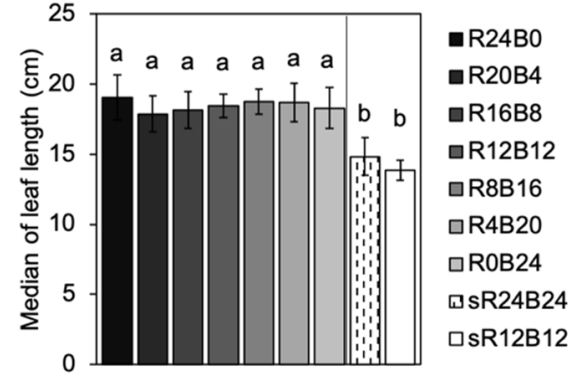

(c) Median of leaf length at each treatment

Fig. 4 (a) A box plot of the leaf length of each plant $(n=10)$. The cross and horizontal bar indicate the mean and the median values, respectively. (b) The frequency line graph of leaf length under each treatment $(n=10)$. (c) The median of leaf length under each treatment (mean $\pm \mathrm{SD}, n=10$ ). The different letters indicate significant differences within Tukey's multiple comparisons $(P<0.05)$.

Table 3 VIF for multicollinearity.

\begin{tabular}{llccccc}
\hline & $\begin{array}{c}\text { Total leaf area } \\
\left(\mathrm{cm}^{2}\right)\end{array}$ & $\begin{array}{c}\text { Number of } \\
\text { leaves }(/ \text { plant })\end{array}$ & $\begin{array}{c}\text { Individual leaf } \\
\text { area }\left(\mathrm{cm}^{2}\right)\end{array}$ & $\begin{array}{c}\text { Specific leaf area } \\
\left(\mathrm{cm}^{2} / \mathrm{g}\right)\end{array}$ & $\begin{array}{c}\text { Stem length } \\
(\mathrm{cm})\end{array}$ \\
\hline \multirow{2}{*}{ Model 1 } & $V I F_{1}$ & $103.9^{* *}$ & $58.2^{*}$ & $61.9^{*}$ & 1.61 & 1.49 \\
& $V I F_{2}$ & - & 1.68 & 1.34 & 1.56 & 1.49 \\
\hline \multirow{2}{*}{ Model 2 } & $V I F_{1}$ & $126.4^{* *}$ & $35.8^{*}$ & $93.1^{*}$ & 1.72 & 1.35 \\
& $V I F_{2}$ & - & 1.32 & 1.65 & 1.72 & 1.27 \\
\hline$* V I F>10, * * V I F>100$ & & & & &
\end{tabular}

$V I F_{n}$ refers to the confirmation of the $n$-th multicollinearity.

The PMs except TLA were found to differently affect the SFW in model 1 compared to model 2 (Fig. 5). A linear independence was detected between the NL and the ILA, i.e., no multicollinearity, because the correlation coefficients between the NL and the ILA in models 1 and 2 were -0.099 and -0.008 , respectively, which were less than 0.1 . In addition, the $P$-values of the standard partial regression coefficients of three parameters: NL, ILA, and SLA, were found to be significant, because they were less than
0.01. On the other hand, the stem length was not an essential factor to determine SFW, since the $P$-value of the standard partial regression coefficient was more than 0.05 .

Multiple regression analysis in sole alternating irradiation treatments

The results of multiple regression analysis using model 1 (Fig. 5a) indicated that the corrected $R^{2}=0.858$. Three factors determined SFW were significant in order of NL, ILA, and SLA based on the absolute values of the stan- 


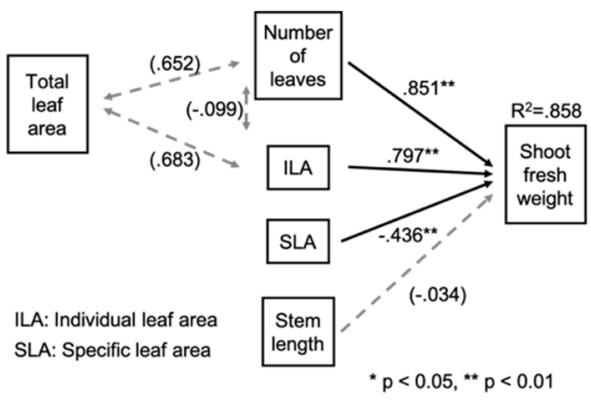

(a) model 1

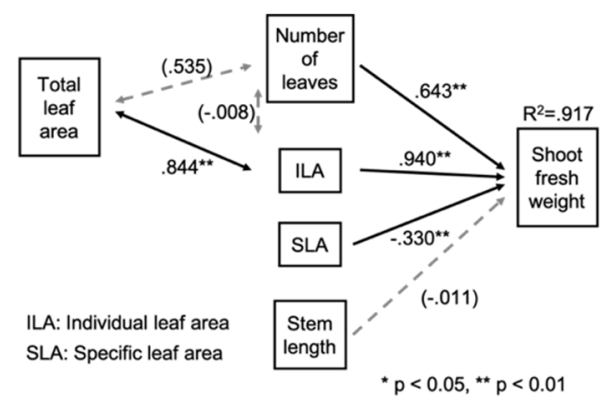

(b) model 2

Fig. 5 A path diagram of model 1 (only alternating irradiation treatments, $n=70$ ) and model 2 (all treatments, $n=90$ ). The single-headed arrows indicate the causal relationships between the plant morphological characteristics and SFW, and the attached numbers represent standard partial regression coefficients. The double-headed arrows indicate the correlations between plant morphological characteristics $(V I F>10)$, and the attached numbers represent correlation coefficients.

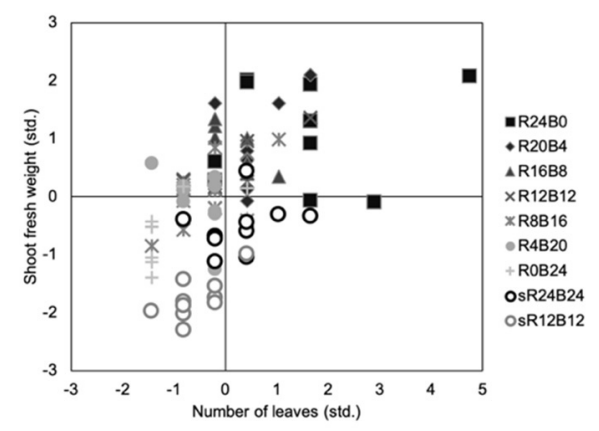

(a) Number of leaves

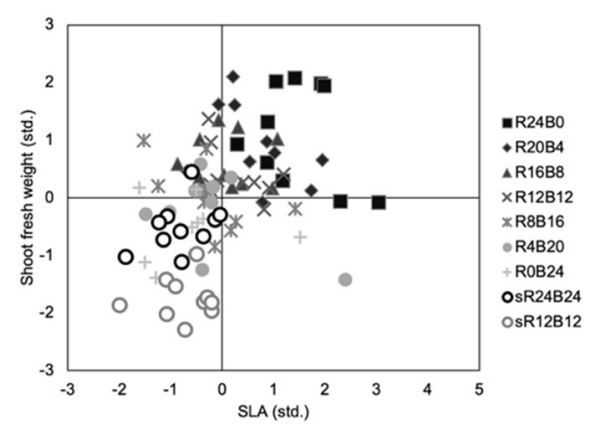

(c) SLA

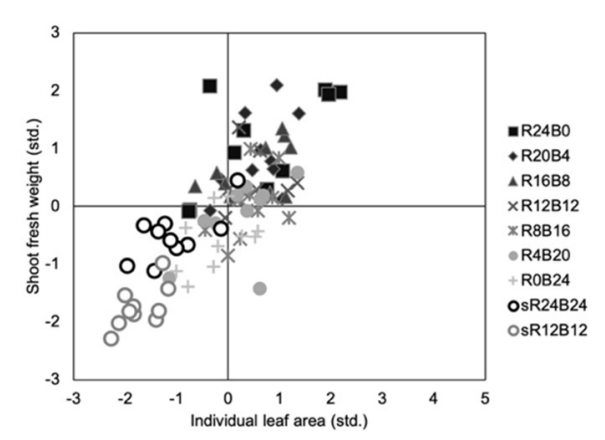

(b) Individual leaf area

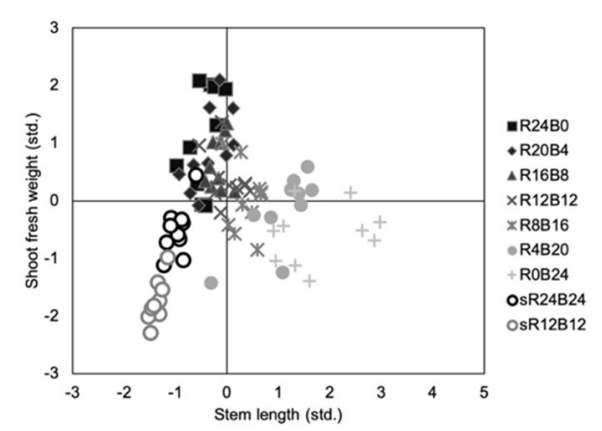

(d) Stem length

Fig. 6 A scatter diagram of the plant morphological characteristics versus SFW (all treatments, $n=90$ ).

dard partial regression coefficients. The positivity or negativity of the standard partial regression coefficient was used as an indication of the increase in the SFW with increasing NL and ILA or the decrease in the SFW with increasing SLA, respectively. Figure 6 shows scatter diagrams that confirm the relationships between each PMs and SFW, in which the NL (Fig. 6a) and ILA (Fig. 6b) exhibit similar variations. In addition, both NL and ILA show a slightly positive correlation, which is consistent with the fact that each standard partial regression coefficient is close. On the other hand, the standard partial regression coefficient of SLA was negative, and its abso- lute value was small (Fig. 6c). However, the correlation coefficient between SLA and SFW was 0.229, a positive value (Table 4). Therefore, SLA was a suppressor variable. When NL and ILA were constant, small SLA, i.e., thick or dense leaves from Eq. 3, was expressed to increase SFW. Moreover, the standard partial regression coefficient of the stem length was estimated to be 0 although there was a slightly negative correlation, -0.469 (Fig. 6d, Table 4). The analyzed results were only those of ALTs, which quantitatively supports hypothesis 1 .

Multiple regression analysis in all treatments

The results of the multiple regression analysis in 
K. MASUDA ET AL.

Table 4 Correlation coefficients between objective and explanatory variables in models 1 and 2 .

\begin{tabular}{l|cccccc}
\hline Model 2 & $\begin{array}{c}\text { Shoot fresh } \\
\text { weight }(\mathrm{g})\end{array}$ & $\begin{array}{c}\text { Total leaf area } \\
\left(\mathrm{cm}^{2}\right)\end{array}$ & $\begin{array}{c}\text { Number of } \\
\text { leaves }(/ \mathrm{plant})\end{array}$ & $\begin{array}{c}\text { Individual leaf } \\
\text { area }\left(\mathrm{cm}^{2}\right)\end{array}$ & $\begin{array}{c}\text { Specific leaf } \\
\text { area }\left(\mathrm{cm}^{2} / \mathrm{g}\right)\end{array}$ & $\begin{array}{c}\text { Stem length } \\
(\mathrm{cm})\end{array}$ \\
\hline Shoot fresh weight $(\mathrm{g})$ & & $0.873^{* *}$ & 0.589 & 0.579 & 0.229 & -0.469 \\
Total leaf area $\left(\mathrm{cm}^{2}\right)$ & $0.929^{* *}$ & & $0.652 *$ & $0.683 *$ & 0.566 & -0.544 \\
Number of leaves $(/ \mathrm{plant})$ & 0.521 & 0.535 & -0.099 & 0.457 & -0.470 \\
Individual leaf area $\left(\mathrm{cm}^{2}\right)$ & $0.776^{* *}$ & $0.844^{* *}$ & 0.008 & 0.328 & -0.269 \\
Specific leaf area $\left(\mathrm{cm}^{2} / \mathrm{g}\right)$ & 0.397 & 0.632 & 0.400 & 0.500 & -0.411 \\
Stem length $(\mathrm{cm})$ & 0.150 & 0.128 & -0.273 & 0.348 & -0.029 \\
\hline
\end{tabular}

model 2 (Fig. 5b) indicate very high corrected $R^{2}=0.917$. Three factors determined SFW were significant in order of ILA, NL, and SLA. As shown in Fig. 6, it was confirmed that the standard partial regression coefficient of the NL was smaller compared to that of the ILA, because there was a tendency for the SFW not to increase under SIMs (Fig. 6a). The positive correlation between ILA and SFW (Fig. 6b) was very high in model 2, which takes SIMs into consideration. This can be attributed to the large standard partial regression coefficient, which acts as a major factor affecting SFW. SLA was a suppressor variable because the standard partial regression coefficient of SLA, and its absolute value and the correlation coefficient with SFW in model 2 had the same trend as in model 1 (Fig. 6c, Table 4). There was a significantly positive correlation between the stem length and SFW only under SIMs (Fig. 6d); however, the fact that the stem length could not be considered as a variable affecting SFW can be attributed to the larger number of treatments conducted under ALTs compared to those conducted under SIMs for the convenience of model design. These analyses of the results under all treatments, i.e., ALTs and SIMs, offers a quantitative support of hypothesis 2 , which assumes that the increase in the ILA leads to the increase in the SFW.

\section{DISCUSSION}

The different effects of ALTs and SIMs on the plant growth and PMs were observed. Furthermore, under ALTs, different percentages of red and blue light periods had different effects on plant growth and PMs. The results of increasing total fresh weight, SFW, SDW and TLA with the increase in the red-light period under ALTs (Table 2) were contrary to those obtained by Ohtake et al. (2018) and Takasu et al. (2019), but they were in accordance with the results of Kuno et al. (2017). The reason for the difference from the results of Ohtake et al. (2018) is believed to be that the combination of red and blue light irradiation intensities differed from this study. Moreover, the results of Takasu et al. (2019) were slightly different from those of this study because they were not able to establish the cultivation conditions set at the same timing as explained in the INTRODUCTION section. However, no significant differences in the highest groups of total fresh weight and SFW were in accordance with those obtained in Takasu et al. (2019). Furthermore, a positive correlation between the
TLA and SFW was also reported by Jishi et al. (2016) and Takasu et al. (2019), and this study can also have found this positive correlation in Table 2. The increase in shoot dry matter ratio with increasing the blue light period under ALTs may have indicate the decrease of the water content, which affects the freshness. It will be necessary to conduct a taste test to see if the leaf lettuce cultivated under ALTs will satisfy consumers.

Increasing the NL with red light under ALTs may have been caused by the difference in the photosynthetic rate of individual leaves for monochromatic red and blue lights. Saito et al. (2012) indicated that the rate of photosynthesis was higher in red light than in blue light. Thus, the daily rate of photosynthesis and the accumulation of photosynthates increased as the duration of red-light exposure increased. Each the ILA at Table 2 and the leaf length at Fig. $4 \mathrm{c}$ indicated that there were no significant differences in ALTs, but SFW differed significantly in ALTs, which may be due to the NL and TLA. On the other hand, under all treatments, there were significant differences of not only the leaf length, which was measured, but also the ILA, which was calculated, between ALTs and SIMs.

The relationships between irradiation patterns, leaf length and ILA were considered from the perspective of photoreceptors and plant hormones. Several plants contain photoreceptors of red and far-red lights such as phytochrome and those of blue light such as cryptochrome and phototropin, and each photoreceptor can be activated by a different wavelength band of light (Han et al., 2013; Paik and Huq, 2019; Warpeha and Montgomery, 2016). The interactions between different photoreceptors in de-etiolation, shade avoidance, phototropism, etc. have been investigated by observing mutants (Ahmad and Jarillo, 1998; Ballare et al., 1992; Casal, 2000, 2012; Franklin, 2016; Goyal et al., 2016). Chen et al. (2017) discussed the possibility that these interactions may also occur in red-blue alternating irradiation, but we will provide a more specific explanation. The short leaf length and small ILA in SIMs may have been caused by phytochrome B (activated by the high ratio of red to far red) and cryptochrome (Ahmad and Jarillo, 1998; Casal, 2012; Paik and Huq, 2019). The interaction of these two photoreceptors downstream of the signaling pathway may have weakened the auxin biosynthesis or flow rate, suppressing the increase in the number of cells, and ultimately limiting leaf elongation (Franklin, 2016; Xiong and Jiao, 2019). If the cell hypertrophy is 
inhibited rather than the number of cells, gibberellin may be involved. It was also possible that the leaf length limit was larger in ALTs, but the leaf length limit in SIMs was reasonable because the leaf length distribution in ALTs containing red and blue monochromatic light tended to be similar (Fig. 4b), and the effect of phytochrome inactivity was less likely to occur because of LEDs without far-red light in the absence of a dark period. This would seem to cause a different phenomenon than shade avoidance. The limited maximum leaf length even in ALTs indicated that phytohormone-induced leaf elongation was limited to a certain extent by single wavelengths.

Multiple regression analyses in both models showed that SLA and the stem length were not important factors for determining the SFW. Within ALTs, there was a decrease in SLA with increasing blue light, i.e., an increase in LT or LD from Eq. 3. Leaf lettuce under SIMs may have even thicker leaves or higher density. Therefore, although the effect on SFW was small, SLA varied depending on the irradiation method and is considered to be an essential factor affecting the eating quality. Furthermore, the distribution strategy of photosynthetic product caused by irradiation patterns and photoreceptors may have affected the photomorphogenesis, e.g., the increase in the TLA and the decrease in the stem length with increasing red-light period under ALTs in Table 2. Especially, the stem length directly influences the plant appearance which is considered an essential factor in determining value. Furthermore, Jishi et al. (2016) discussed that it was more likely to fall if the plant height was higher. Therefore, it will be necessary to regulate the stem length, and this study indicated that increasing the irradiation time of blue monochromatic light induced the elongation of the stem length.

TLA, NL, ILA, SLA, and stem length are basic plant morphological characteristics, and the combination of these characteristics may determine the canopy and projected area of the plant and thus the SFW. The results of multiple regression analysis in this study indicate that ILA has the largest effect on the projected area between ALTs and SIMs, and NL has the largest effect on the canopy structure of plants within ALTs.

\section{CONCLUSION}

In this study, leaf lettuce (Lactuca sativa L. var. crispa 'Greenwave') was used to quantify the differences in the PMs and determine the effects of alternating redblue and simultaneous irradiations on the plant growth. The alternating red and blue irradiations from LED resulted in longer leaf length and larger ILA compared with simultaneous irradiations, which eventually led to an increase in SFW. On the other hand, the increase in the redlight period during the alternating irradiation treatments resulted in increasing the NL and consequently the TLA. The largest SFW value was obtained using only red monochromatic light in all irradiation treatments.

Furthermore, multiple regression analysis revealed that it was possible to quantitatively determine which parameter among the PMs had the largest contribution to
SFW. The order of the parameters affecting SFW in case of alternating red-blue irradiation treatments was as follows: the NL, ILA, SLA, while that considering all irradiation treatments was as follows: the ILA, NL, SLA. A hypothesis that suggests an increase in the SFW was constructed according to the effects of irradiation patterns on PMs and SFW. This hypothesis was reinforced by the results of the experiment studying the effects of each PMs on the SFW.

Future studies should examine the photomorphogenesis based on the interaction of photoreceptors such as phytochrome and phototropin. In addition, the phenotyping techniques and multiple regression analysis used in this study should be performed for other varieties of leaf lettuce and different conditions because the case of 'Greenwave' has solely been investigated in this study.

\section{ACKNOWLEDGMENTS}

The first and corresponding author KM would like to thank late Prof. Hiroshi Shimizu for his valuable guidance on KM's experiments for undergraduate thesis, without which this study cannot be accomplished.

\section{REFERENCES}

Ahmad, M., Jarillo, J. A. 1998. The CRY1 blue light photoreceptor of Arabidopsis interacts with phytochrome A in vitro. Mol. Cell 1: 939-948.

Akinwande, M. O., Dikko, H. G., Samson, A. 2015. Variance inflation factor: as a condition for the inclusion of suppressor variable(s) in regression analysis. Open J. Stat. 5: 754-767.

Ballare, C. L., Scopel, A. L., Radosevich, S. R., Kendrick, R. E. 1992. Phytochrome-mediated phototropism in de-etiolated seedlings: occurrence and ecological significance. Plant Physiol. 100: 170-177.

Benke, K., Tomkins, B. 2017. Future food-production systems: vertical farming and controlled-environment agriculture. Sustain. Sci. Pract. Policy. 13: 13-26.

Casal, J. J. 2000. Phytochromes, cryptochromes, phototropin: photoreceptor interactions in plants. Photochem. Photobiol. 71: $1-11$.

Casal, J. J. 2012. Shade avoidance. Arabidopsis Book 10: e0157.

Chen, X. L., Yang, Q. C., Song, W. P., Wang, L. C., Guo, W. Z., Xue, X. Z. 2017. Growth and nutritional properties of lettuce affected by different alternating intervals of red and blue LED irradiation. Sci. Hortic. 223: 44-52.

Franklin, K. A. 2016. Photomorphogenesis: plants feel blue in the shade. Curr. Biol. 26: 1272-1296.

Goto, E. 2012. Plant production in a closed plant factory with artificial lighting. Acta Hortic. 956: 37-49.

Goyal, A., Karayekov, E., Galvao, V. C., Ren, H., Casal, J. J. 2016. Shade promotes phototropism through phytochrome B-controlled auxin production. Curr. Biol. 26: 3280-3287.

Han, I. S., Cho, H. Y., Moni, A., Lee, A. Y., Briggs, W. R. 2013. Investigations on the photoregulation of chloroplast movement and leaf positioning in Arabidopsis. Plant Cell Physiol. 54: 4856.

Hanyu, H., Shoji, K. 2002. Acceleration of growth in spinach by short-term exposure to red and blue light at the beginning and at the end of the daily dark period. Acta Hortic. 580: $145^{-}$ 150 . 
ImageJ. 2018. https://imagej.nih.gov/ij/ (accessed on May 31, 2020)

Jishi, T., Kimura, K., Matsuda, R., Fujiwara, K. 2016. Effects of temporally shifted irradiation of blue and red LED light on cos lettuce growth and morphology. Sci. Hortic. 198: 227-232.

Kozai, T. 2013. Plant factory in Japan - current situation and perspectives. Chron. Hortic. 53: 8-11.

Kuno, Y., Shimizu, H., Nakashima, H., Miyasaka, J., Ohdoi, K. 2017. Effects of irradiation patterns and light quality of red and blue light-emitting diodes on growth of leaf lettuce ( $\mathrm{Lac}$ tuca sativa L. "Greenwave"). Environ. Control Biol. 55: 129135.

Mansfield, E. R., Helms, B. P. 1982. Detecting multicollinearity. Am. Stat. 36: 158-160.

Marquardt, D. W. 1970. Generalized inverses, ridge regression and biased linear estimation. Technometrics 12: 591-612.

Mohr, H., Schopfer, P. 1998. Pflanzenphysiologie. SpringerVerlag, Berlin, pp 598.

O'Brien, R. M. 2007. A caution regarding rules of thumb for variance inflation factors. Qual. Quant. 41: 673-690.

Ohtake, N., Ishikura, M., Suzuki, H., Yamari, W., Goto, E. 2018. Continuous irradiation with alternating red and blue light enhances plant growth while keeping nutritional quality in lettuce. HortScience 53: 1804-1809.

Paik, I., Huq, E. 2019. Plant photoreceptors: multi-functional sensory proteins and their signaling networks. Semin. Cell Dev. Biol. 92: 114-121.

Saito, Y., Shimizu, H., Nakashima, H., Miyasaka, J., Ohdoi, K. 2012. Comparison of the effects of monochromic red light and mixed light on the growth of lettuce. (in Japanese) J. Soc. High Technol. Agric. 24: 25-30.

Shimokawa, A., Tonooka, Y., Matsumoto, M., Ara, H., Suzuki, H., Yamauchi, N., Shigyo, M. 2014. Effect of alternating red and blue light irradiation generated by light emitting diodes on the growth of leaf lettuce. bioRxiv. 2014. doi: http://dx. doi.org/10.1101/003103

Shimokawa, A., Tonooka, Y., Matsumoto, M., Hirata, S., Ara, H., Suzuki, H., Yamauchi, N., Shigyo, M. 2020. Development of next-generation light irradiation techniques for Japanese plant factory system powered by light-emitting diode. Acta Hortic. 1271: 85-92.

Takasu, S., Shimizu, H., Nakashima, H., Miyasaka, J., Ohdoi, K. 2019. Photosynthesis and morphology of leaf lettuce (Lactuca sativa L. cv. Greenwave) grown under alternating irradiation of red and blue light. Environ. Control Biol. 57: 93-98.

Warpeha, K. M., Montgomery, B. L. 2016. Light and hormone interactions in the seed-to-seedling transition. Environ. Exp. Bot. 121: 56-65.

Xiong, Y., Jiao, Y. 2019. The diverse roles of auxin in regulating leaf development. Plants 8: 243. 